\title{
Effection of Rainfall in summer on the landscape water in green area of Beijing
}

\author{
Haiqi Wei, a ${ }^{1,}$ Fan $\mathrm{Fu}^{{ }^{2}, \mathrm{~b}}$ Xinye $\mathrm{Wu}^{3, \mathrm{c}}$, Tianxiong $\mathrm{Yin}^{4, \mathrm{~d}}$, Zichao Fan ${ }^{5, \mathrm{e}}$ \\ ${ }^{1,2,3,4,5}$ North China University of Technology,Jin Yuan Zhuang Road No. 5, \\ Shijingshan District,Beijing,China \\ a921661243@qq.com, bmattbff@163.com, \\ '851160780@qq.com, ${ }^{\mathrm{d} y t x 0710 @ q q . c o m,{ }^{\mathrm{e}} 17729895232 @ q q . c o m}$
}

\begin{abstract}
Keywords: Stormwater runoff; Landscape water; Fluctuation of water quality
Abstract. As an important part of urban green area, especially the parks in the city, the fluctuation of the water quality of water landscape has become the focus of urban ecological environment. Due to the rapid development of urbanization, urban hardened area ( such as roofing, paving roads, etc. ) continues to increase, causing the accumulation of pollutants. Therefore, urban stormwater runoff which carries large amounts of pollutants has a great impact on landscape water in the urban green space. Considering this, a three-month water quality monitoring was carried out in this paper using Hach water quality tester to test three typical bodies of water which have different origins and source of pollution during the rainy season of Beijing. The results showed that urban stormwater runoff may have serious impact on the quality of landscape water.
\end{abstract}

\section{Introduction}

Water landscape is an important part of urban green area, especially the parks in the city. It has many functions which can benefit the landscape structure, irrigation and water supply, water detention and flood control as well as biodiversity. Stormwater runoff has become one of the main source of pollution of urban water environment. Owing to the rapid urbanization, impermeable land surface such as business center, residential area, roads and parking lots have increased leading to the decrease of stormwater permeating into the underground. Therefore, surface runoff becomes increasingly much. Under the influence of the of surface runoff's scour, much pollution that exists on the ground goes into the water body and then change the physical, chemical and biological properties of the water, becoming the main element which influences the water quality[1].

The major indexes of the monitoring are COD, BOD, Total nitrogen(TN), total phosphorus(TP) and ammonia nitrogen(NH3-N.) and TSS[2]. Through the monitoring of pollutant concentration of landscape water both in sunny weather and rainy days and then comparing the results with the Class IV water standard in Environmental Quality Standards for Surface Water [3], The change of water quality and pollution caused by stormwater was analyzed and the suggestions were put forward.

\section{Methodology}

Research Areas. To study the influence of stormwater in summer to the landscape water of green area in Beijing, Yuyuantan Park, Olympic Forest Park and The Summer Palace were chosen as the three research areas. Yuyuantan occupies a total area of 136.69 hectares and boasts 74 hectares of water area which originates from Jingmi and diversion canal of Yongding. Its Green coverage rate reaches over $95 \%$ and boasts about 199,500 types of plants[4]. Beijing Olympic Forest Park is next to the the Olympic stadium area in the south, close to the suburban greenbelt in the north and stretches across the city's main loop ( the North Fifth Ring ). Beijing Olympic Forest Park occupies a total area of 68,000 hectares ( 12,200 hectares of water area, the vast majority of the water is still water ) and its plant coverage reaches 90\%[5]. Summer Palace covers an area of 290 hectares. The surface area of 
Kunming lake in the Summer Palace accounts for about $78 \%$ of the entire park. The water in Summer Palace originates from Yuquan Hill, Changping diversion and Jingmi diversion.

Monitoring Method. Hach water quality testing meter is used to monitor the indexes such as COD, BOD, Total nitrogen, total phosphorus and ammonia nitrogen and TSS, etc. The monitoring spots are set up based on the characteristics of the research areas. According to the Water and Exhausted Water Monitoring Analysis Method, every spot is set up in the place blow the water surface

\section{Monitoring Results and Analysis}

COD Monitoring Result Analysis." Environment Quality Standards for Surface Water " (G3838-2002) in China provides that the allowable value of COD in Table 2.

Table 1:Standard of COD

\begin{tabular}{|l|l|l|l|l|l|}
\hline & Class I & Class II & Class III & Class IV & Class V \\
\hline $\mathrm{COD} \leq$ & 15 & 15 & 20 & 30 & 40 \\
\hline
\end{tabular}

As shown in Figure 1, the main lake in the Olympic Forest Park, the summer palace Kunming Lake, Yuyuantan East Lake water quality generally of rainfall weather worse than sunny weather. The curve fluctuation of the three research areas is more uniform.COD concentration in July 19th was better than July 6th.Because of the rainstorm in July 19th, a large amount of water, the water flow speed, enhance self-purification capacity of COD. During the period, a large amount of water, the water flow high speed, enhance self-purification capacity of COD. No matter rain or non-rainfall weather conditions, Kunming Lake reached class IV standard. Olympic Forest Park lake only in May 12th COD in the V class. Other monitoring dates are in line with the IV class. Yuyuantan East Lake in July 6th sunny weather conditions, COD exceeded the class IV water standard, which belongs to the class V water. The results of the three study areas COD concentration show that Yuyuantan East Lake> Olympic Forest Park Lake> Kunming Lake. Therefore, the Kunming lake water quality is best, Yuyuantan East Lake is relatively poor.

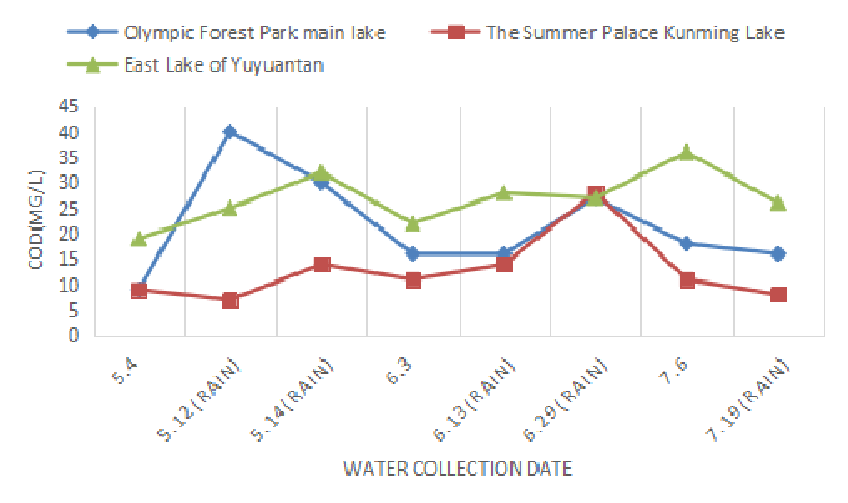

Fig1: COD in landscape water

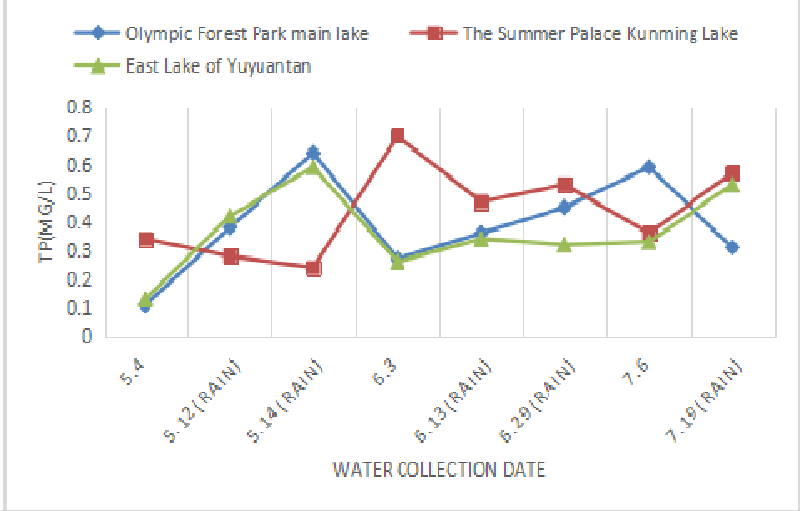

Fig2: TP in landscape water

TP Monitoring Result Analysis. "Environment Quality Standards for Surface Water " (G3838-2002) in China provides that the allowable value of TP in Table 3.

Table 2:Standard of TP

\begin{tabular}{|l|l|l|l|l|l|}
\hline & Class I & Class II & Class III & Class IV & Class V \\
\hline TP $\leq$ & 0.02 & 0.1 & 0.2 & 0.3 & 0.4 \\
\hline
\end{tabular}

As shown in Figure 2, comprehensive study of the TP data in all areas, only $25 \%$ of the data in compliance with the IV class, $33 \%$ belong to the V class, $42 \%$ belong to the inferior V class. On sunny days, the TP were also in excess of the IV class standards. That total phosphorus in water of Beijing parks seriously exceed the standard. The Olympic Forest Park and Yuyuantan east lake fluctuation curve of regularity is similar. The overall trend of the TP in the rain water was increased. The fluctuation of Kunming lake has a completely opposite trend with the other two research areas. The 
trend of TP in Kunming lake is decreased in the presence of rainfall. The TP in Kunming lake was generally very high of sunny days, all of which belonged to V class and inferior V class standard.

TN Monitoring Result Analysis. "Environment Quality Standards for Surface Water " (G3838-2002) in China provides that the allowable value of TN in Table 4.

Table 3: Standard of TN

\begin{tabular}{|l|l|l|l|l|l|}
\hline & Class I & Class II & Class III & Class IV & Class V \\
\hline $\mathrm{TN} \leq$ & 0.2 & 0.5 & 1.0 & 1.5 & 2.0 \\
\hline
\end{tabular}

As shown in Figure 3, there is similar to that of Kunming lake and the Olympic Forest Park Lake in the rainfall and sunny weather conditions of total nitrogen concentration fluctuation curve. The TN concentration of rainfall is higher than that of sunny weather. And in the May, June, July TN in the water there is a gradual downward trend. The main reason is that the plant is flourishing in summer, which can effectively purify the water quality. Kunming lake and the Olympic Forest Park curve is similar to the law of fluctuation. But the TN in the main lake of Olympic higher than that of Kunming Lake. The TN in Kunming lake is consistent with the IV standard. The TN of the Olympic Forest Park in June and July was in accordance with the III standard. V class standards for rainfall conditions. In May, that was badder than $\mathrm{V}$ criterion. Yuyuantan is different from the other two study area fluctuation. Shows that the first time rain water $\mathrm{TN}>$ sunny weather water $\mathrm{TN}>$ second rain water $\mathrm{TN}$.

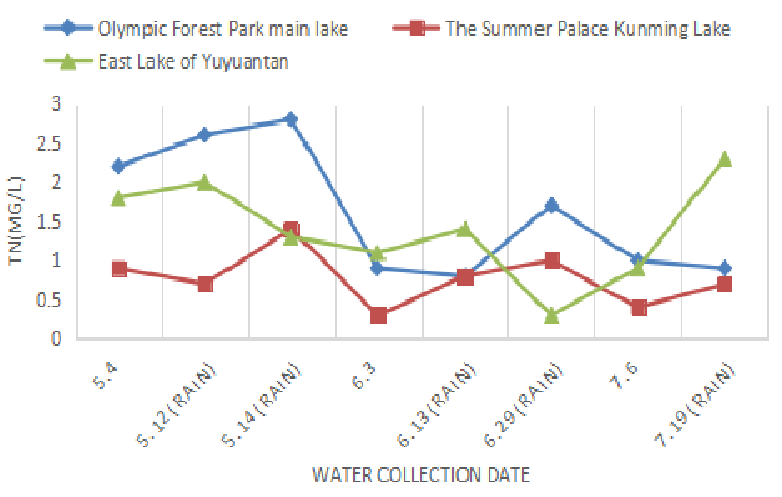

Fig3: TN in landscape water

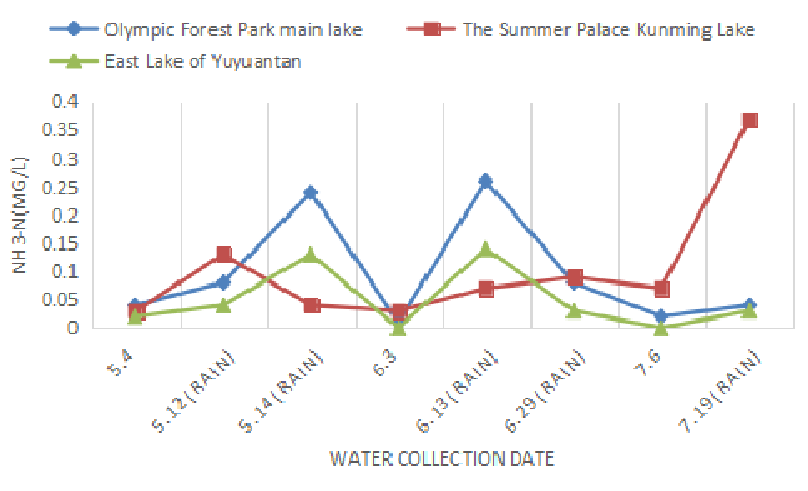

Fig4: NH3-N in landscape water

NH3-N Monitoring Result Analysis. "Environment Quality Standards for Surface Water " (G3838-2002) in China provides that the allowable value of $\mathrm{NH}_{3}-\mathrm{N}$ in Table 5.

Table 4: Standards of NH3-N

\begin{tabular}{|l|l|l|l|l|l|}
\hline & Class I & Class II & Class III & Class IV & Class V \\
\hline $\mathrm{NH} 3-\mathrm{N} \leq$ & 0.15 & 0.5 & 1.0 & 1.5 & 2.0 \\
\hline
\end{tabular}

As shown in Figure 4, three research sites showed significantly higher concentration of NH3-N in water under the condition of rainfall weather trend. But from the curve trend, changes of main lake of Olympic Forest Park and East Lake of Yuyuantan are more similar. To analyze the water quality of the three research areas. Whether it is rain or sunny weather conditions the concentration of NH3-N can reach II standards. It shows that the water of park green space in Beijing is very good for the control of the pollutant index of NH3-N.

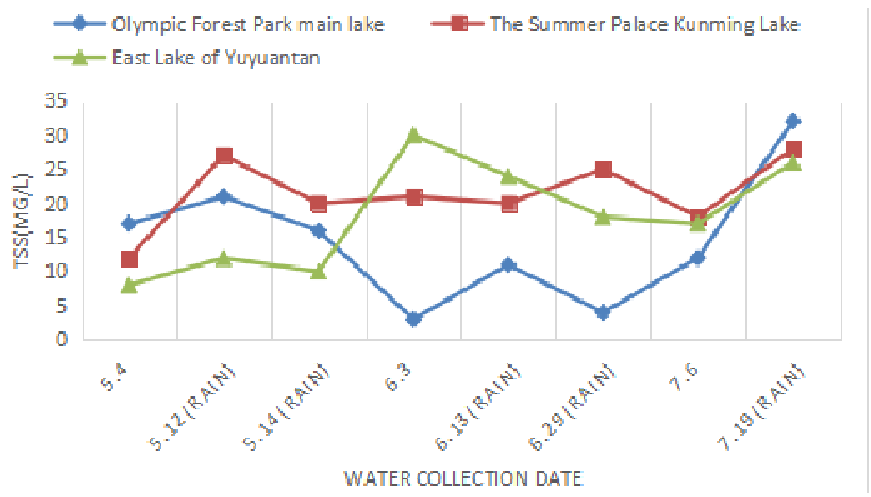

Fig5: TSS in landscape water 
TSS Monitoring Result Analysis. As shown in Figure 5, three study area in sunny weather with rains variation of TSS concentration there was a similarity, substantially higher than the TSS rains sunny weather.TSS rainfall is higher than the fine weather. Is the Yuyuantan cruise activities frequently mainly due to the peak in June 3 rd in the sunny weather situation. Human activity has a certain effect on the concentration of TSS in water.

\section{Conclusions}

According to the water quality monitoring of three landscape water for a period of three months in Beijing .It can be observed that the pollution caused by the rain water runoff from the urban rain water can cause a serious impact on the landscape water body. There are some main reasons for the difference in the degree of water pollution from the storm water runoff. First, the water resources of the three study areas are different, and there are obvious differences in the various indicators. Second, the degree of natural revetment is caused by the different influence degree of runoff are important reason for the difference. Compared with artificial hardening revetment the natural revetment can reduce runoff velocity and to reduce the pollutant in the process of transmission. Third, differences in the amount of water in the water is also one of the factors. Root, stem and leaf of plant can play a certain role interception of rainwater runoff.

Through comparative analysis. To better control and optimize the landscape water quality and reduce the impact on water quality of rainwater runoff. Firstly, it should be done on water sources quality control. Proposed the corresponding solution strategies for pollutant index to highlight governance. If necessary it will create artificial rain wetlands, grassed swales, sunken green space, rain gardens and other green infrastructure to purify water. And pay attention to the amount of water on plant cultivation and conservation. Reasonable revetment and planting with aquatic plants can effectively alleviate the pollution of stormwater runoff. While the planning and design stage for large landscape waters should avoid excessive hard revetment, reducing the possibility of stormwater runoff directly into the water body landscape.

\section{Acknowledgments}

This work was financially supported by Scientific Research Training program for College Students---Study on comprehensive ecological benefits of Constructed Wetland.Item status coding:(XN001-105).

\section{References}

[1] LI Li-qing, YIN Cheng-qing, KONG Ling-li, HE Qing-ci:Effect of Antecedent Dry Weather Period o $n$ Urban Storm Runoff Pollution Load,edtied by enviromental science,2287-2293(2007).

[2] CHEN Si-jia, SU De-rong,Comparison and monitoring of water quality in different water area of urban green space in Beijing,edtied by Journal of Central South University of Forestry\&Technology,122-149(2013).

[3] The People's Republic of China Standard. GB3838-2002.

[4] Xiao Xiong-fang,The Comparative Study of Recreational Characteristic on The Greenway and City Park Users,(2014).

[5] HU Jie, WU Yi- xia, LV Lu- shan,Water System Plan of Beijing Olympic Forest Park,edtied by Chinese garden,14-19(2006). 